\title{
Erratum to: Next generation sequencing uncovers a missense mutation in COL4A1 as the cause of familial retinal arteriolar tortuosity
}

Juan C. Zenteno ${ }^{1}$ - Jaume Crespí ${ }^{2} \cdot$ Beatriz Buentello-Volante $^{1}$. Jose A. Buil ${ }^{2}$ - Francisca Bassaganyas ${ }^{2}$ - Jose I. Vela-Segarra ${ }^{2}$. Jesus Diaz-Cascajosa $^{2} \cdot$ Maria T. Marieges $^{2}$

Published online: 4 July 2015

(C) Springer-Verlag Berlin Heidelberg 2015

Erratum to: Graefes Arch Clin Exp Ophthalmol (2014) 252:1789-1794

DOI 10.1007/s00417-014-2800-6

The original version of this article inadvertently contained mistake. Affiliation number 2 should have been:

Department of Ophthalmology, Autonomous University of Barcelona, Hospital de Sant Pau y de la Santa Creu, Barcelona, Spain

Correct presentation given below.

The online version of the original article can be found at http://dx.doi.org/ 10.1007/s00417-014-2800-6.

Juan C. Zenteno

jczenteno@institutodeoftalmologia.org

1 Genetics Department and Research Unit, Institute of Ophthalmology "Conde de Valenciana" and Biochemistry Department, Faculty of Medicine, National Autonomous University of Mexico (UNAM), Chimalpopoca 14, Col. Obrera, Mexico City, CP 06800, Mexico

2 Department of Ophthalmology, Autonomous University of Barcelona, Hospital de Sant Pau y de la Santa Creu, Barcelona, Spain 